\title{
INOVAÇÃO DISRUPTIVA: UM OLHAR SOBRE OS AMBIENTES EDUCATIVOS INOVADORES
}

\section{DISRUPTIVE INNOVATION: AN OVERVIEW ABOUT THE INNOVATIVE LEARNING ENVIRONMENTS}

\author{
Clarice Parreira Senra \\ Universidade Federal de Juiz de Fora/Departamento de Educação/FACED, \\ CEFET/RJ/Programa de Pós-Graduação em Ciência, Tecnologia e Educação \\ claricesenra@yahoo.com.br

\section{Marco Braga} \\ CEFET/RJ/Programa de Pós-Graduação em Ciência, Tecnologia e Educação, \\ marcobraga@namelab.education
}

\section{Resumo}

Os Ambientes Educativos Inovadores (AEI) surgem no contexto da sala de aula na tentativa de promover práticas inovadoras e as chamadas competências do século XXI. O presente estudo foi realizado a partir de informações sobre o processo de implementação de Ambientes Educativos Inovadores no contexto de 4 escolas portuguesas. A investigação consistiu na coleta de informações a partir de 3 fontes de informação básicas: vídeos de aulas previamente gravadas no $\mathrm{AEI}$, entrevista com 9 professores e observação de atividades. A partir do conceito de inovação disruptiva analisamos a implementação desses AEl no contexto português, procuramos observar três possíveis posturas apresentadas pelos professores e alunos durante o processo de implementação dos AEI, sendo elas: Rejeição, Affordance e crença no Poder Mágico do $\mathrm{AEI}$ como meio de transformação do ensino. Dessa análise entende-se que o $\mathrm{AEI}$ compreendido como inovação disruptiva rompe com o modelo tradicional de sala de aula e para que esse ambiente atinja o potencial prometido, alunos e professores precisam reconhecer o potencial desse novo ambiente. $O$ docente precisa transformar sua prática e não apenas incorporá-la em um novo espaço.

Palavras-chave: Inovação educacional; Professores; Alunos; Espaço da sala de aula.

\section{Abstract}

Innovative Educational Environments (AEIs) arise in the context of the classroom in an attempt to promote innovative practices and the so-called skills of the 21 st century. The present study was based on information about the process of implementation of Innovative Educational Environments in the context of 4 Portuguese schools. The research consisted of the collection of information from 3 basic information sources: videos of classes previously recorded in the $\mathrm{AEI}$, interview with 9 teachers and observation of activities. From the concept of disruptive innovation we analyze the implementation of these $\mathrm{AEI}$ in 
the Portuguese context, we try to observe three postures posed by the teachers and students during the implementation process of the AEI, being: Rejection, Affordance and belief in the Magic Power of AEl as a means of transformation of education. From this analysis it is understood that the AEI understood as disruptive innovation breaks with the traditional classroom model and for this environment to reach the promised potential, students and teachers need to recognize the potential of this new environment. The teacher needs to transform his practice and not just incorporate it into a new space.

Keywords: Educational innovation; Teachers; Students; Classroom space.

\section{Introdução}

Vários setores de nossa sociedade mudaram com a presença das Novas Tecnologias de Informação e Comunicação (NTIC). As escolas incluíram as tecnologias nas salas tradicionais para melhorar a forma como já ensinavam, sem mudar os métodos de ensino. Mas porque a inserção de computadores nas escolas, por exemplo, não provocou grandes transformações na educação?

Vários programas e projetos foram implementados na educação brasileira, como Proinfo (Programa Nacional de Tecnologia Educacional) e projetos a ele associados: o Projeto um computador por aluno (UCA), o Programa um computador por aluno (PROUCA), o Programa banda larga nas escolas (PBLE) e distribuições de tablets para os alunos. Estudos realizados pelo CETIC.br (Centro de Estudos sobre as Tecnologias da Informação e da Comunicação) sobre esses projetos mostram que as escolas que receberam os equipamentos tiveram dificuldades de utilizá-los devido a falta de infraestrutura, falta de formação (LINHARES e FERREIRA, 2012; SEIXAS, 2011) e suporte técnico para seu uso.

A inserção de tecnologia na sala por si só não muda os modelos de ensino.

Não são os recursos que definem a aprendizagem, são as pessoas, o projeto pedagógico, as interações, a gestão. Mas não há dúvidas de que o mundo digital afeta todos os setores, as formas de produzir, de vender, de comunicar-se e de aprender (MORAN, 2013, p. 12).

Quando se pensa na inserção das tecnologias nas escolas é necessário pensar as metodologias que serão utilizadas. A reprodução de uma pedagogia que tem como foco o professor transmissor vai apenas reforçar o uso de novas técnicas presas a velhos métodos. Diversos autores (CHISM, 2006; MONAHAN, 2002) consideram que o espaço físico tem influência nas práticas realizadas pelo professor. Uma sala com carteiras enfileiradas e o professor como figura central transmite a ideia do "eu falo", você "escuta". Um ambiente com mesas com 4 cadeiras incentiva o trabalho colaborativo (CHISM, 2006). Monahan (2002) usou o termo "pedagogia construída" para se referir às incorporações arquitetônicas de filosofias educacionais.

O espaço acaba por moldar o tipo de aprendizado que acontece nele. A partir dessa filosofia, vem surgindo em todo o mundo diversos projetos com o objetivo de integrar esses 3 elementos: espaço, tecnologia e metodologia. Na constituição desses novos ambientes, várias denominações foram criadas, como "Sala de Aula Moderna" 
(LEAHY, 2016), "Ambientes Educativos Inovadores" (ERTE, 2018) ou "Sala de Aula do Futuro" (EUROPEAN SCHOOLNET, 2016). A criação desses novos ambientes educativos tem sido um movimento de implantação governamental e ao mesmo tempo um processo de experimentação. Dois projetos vêm se destacando no cenário internacional:

- Innovative Learning Environments and Teacher Change (ILETC) (IMMS et al., 2017) - Projeto que reúne pesquisadores na área da educação, design e arquitetura para o estudo da implementação dos Ambientes Educativos Inovadores. A pesquisa vem sendo desenvolvida na Austrália e Nova Zelândia sob o comando da Universidade de Melbourne, durante o período 2016-2019. O foco desse projeto não é a implementação de novos ambientes, já que esses países contam com grande número de ambientes em funcionamento. Seu foco é estudar as influências de diversas características dos AEI sobre a aprendizagem e as formas como os professores vêm ressignificando suas experiências neste contexto.

- Future Classroom Lab (FCL) (EUROPEAN SCHOOLNET, 2016) - Projeto europeu criado pela European Schoolnet (EUN), financiado por 31 Ministérios da Educação. O projeto conta com uma sala "mockup" criada em 2012 em Bruxelas onde são testadas novas tecnologias e ministrados cursos de formação de professores. A sala é constituída por 6 diferentes zonas de aprendizagem: Criar, Interagir, Apresentar, Investigar, Partilhar e Desenvolver (figura 1). Em cada uma dessas zonas procura-se desenvolver diferentes competências e dinâmicas de aprendizagem (PEDRO, 2017). O projeto tem como proposta um novo design para a sala de aula, um repensar das metodologias com incentivo à integração das tecnologias em contexto de sala de aula e aplicativos de suporte a colaboração internacional entre os membros.

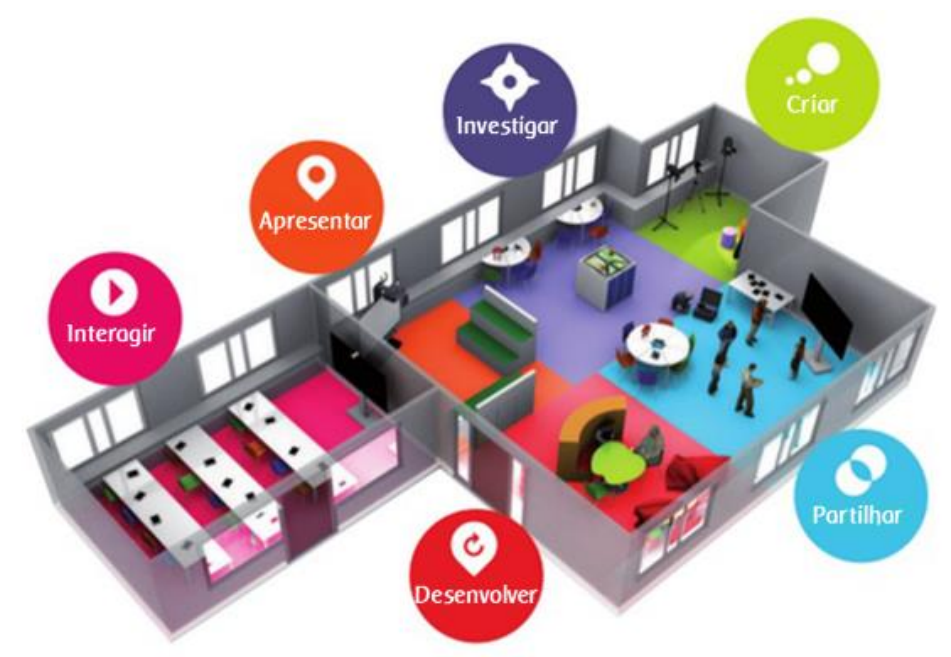

Figura 1 - Sala FCL

Fonte: < http://erte.dge.mec.pt/node/92>

Segundo dados da European Schoonelt existem várias salas de aulas designadas como FCL, sendo que Portugal é hoje o país com maior quantidade de salas instaladas. Praticamente todas foram inspiradas no projeto europeu $\mathrm{FCL}$, e designadas em língua portuguesa por Ambientes Educativos Inovadores (ERTE, 2018). Em 2017 já tinham sido implementadas 34 salas no contexto português (BANNISTER, 2017). A iniciativa das 
salas começou no segundo semestre de 2014, com apoio da Direção Geral da Educação (DGE) em parceria com EUN. O país tem apresentado destaque na implantação deste projeto europeu e revela já uma experiência acumulada neste domínio nos últimos anos.

Devido a isso, a experiência portuguesa vem se tornando exemplar para todos os parceiros do projeto FCL, por ser o país com maior número de salas e por não existir uma regra para a implantação destes espaços. Das 34 salas criadas até 2017 pode-se encontrar uma grande variedade de modelos de implementação, alinhados mais com a realidade local do que com algum modelo que possa gerir o processo.

Apesar do grande investimento na implementação dos AEI, faltam estudos que avaliam o impacto destes ambientes na prática dos professores e na aprendizagem dos alunos (BYERS e IMMS, 2017). É importante questionar se os AEI vão de fato provocar mudanças significativas no ensino, não sendo apenas uma moda, ou mais um projeto como foram outros no campo da educação.

Sabemos que os processos de inovação passam por fases e podem ser ou não adotados pelos os consumidores. Entender o conceito de Inovação Disruptiva (CHRISTENSEN, HORN e JOHNSON, 2012), sua origem e como ter sucesso, pode ajudar a encontrar um caminho possível para que os AEI possam de fato impactar o ensino e não ser apenas mais um projeto que logo será esquecido e abandonado pela escola.

Nosso objetivo neste artigo é discutir o AEI no contexto português a partir do conceito de inovação disruptiva, destacando três possíveis posturas apresentada pelos professores e alunos durante o processo de implementação dos $\mathrm{AEI}$, sendo elas: Rejeição, Affordance e crença no Poder Mágico do AEl como meio de transformação do ensino.

\section{Ambientes Educativos Inovadores}

O tema "Ambiente Educativo Inovador" é recente no campo educacional, sendo difícil encontrar reflexões mais aprimoradas sobre o assunto. As pesquisas sobre esses novos espaços de aprendizagem abarcam vários campos de estudo, desde a arquitetura do espaço ao mobiliário e artefatos tecnológicos nele utilizados. Países como Austrália, Nova Zelândia e Estados Unidos da América têm investido recursos na implementação de $\mathrm{AEI}$, considerando que esses locais podem facilitar o desenvolvimento de competências para o século XXI (BYERS; IMMS; HARTNELL-YOUNG, 2018).

Um espaço, para ser considerado inovador, necessita muito mais do que uma mudança no design da sala, nos mobiliários e nos equipamentos. Precisa propiciar práticas e aprendizagens inovadoras. No relatório Innovative Learning Environments and Teacher Change Defining key concepts, Mahat et al. (2018) apresentam uma definição para Ambiente Educativo Inovador ${ }^{1}$, ou Innovative Learning Environments (ILE), como é chamado em Língua Inglesa:

\footnotetext{
1 Nesta pesquisa, será utilizado o termo em Português: "Ambientes Educativos Inovadores" para referir ao termo em Inglês "Innovative Learning Environments", algumas traduções utilizam "Ambientes de Aprendizagem Inovadores". Optamos por utilizar o termo: "Ambientes Educativos Inovadores", que é utilizado em Portugal para designar seu projeto de implementação de espaços desenhados para o desenvolvimento de atividades que promovem aprendizagem ativa,
} 
Um AEI é definido como o produto de design de espaços inovadores e práticas de ensino e aprendizagem inovadoras. Somente quando estes dois fenômenos são integrados com sucesso, é que produzimos um Ambiente Educativo Inovador. Um design pode ser considerado "inovador", mas só se torna um Ambiente Educativo Inovador quando seus habitantes (alunos e professores) ensinam e aprendem também de forma inovadora dentro deles (MAHAT et al., 2018, pág. 8, tradução autores)².

Como destacado nessa definição, um Ambiente Educativo Inovador precisa integrar elementos de design do espaço físico que propiciem diferentes formas de trabalho, oferecendo flexibilidade. Dovey e Fisher (2014) apresentam distintos tipos de espaços, que variam dos tradicionais aos mais abertos. Esses podem ser classificados em 5 tipos (IMMS; CLEVELAND; FISHER, 2016; IMMS et al., 2017):

a) Tipo A - Sala de aula tradicional fechada;

b) Tipo B - Sala de aula tradicional com espaço aberto (Breakout Space);

C) Tipo C - Sala de aula tradicional com paredes móveis e espaço aberto;

d) Tipo D - Plano aberto com possibilidade de separação das salas;

e) Tipo E - Plano aberto com alguns espaços adjacentes.

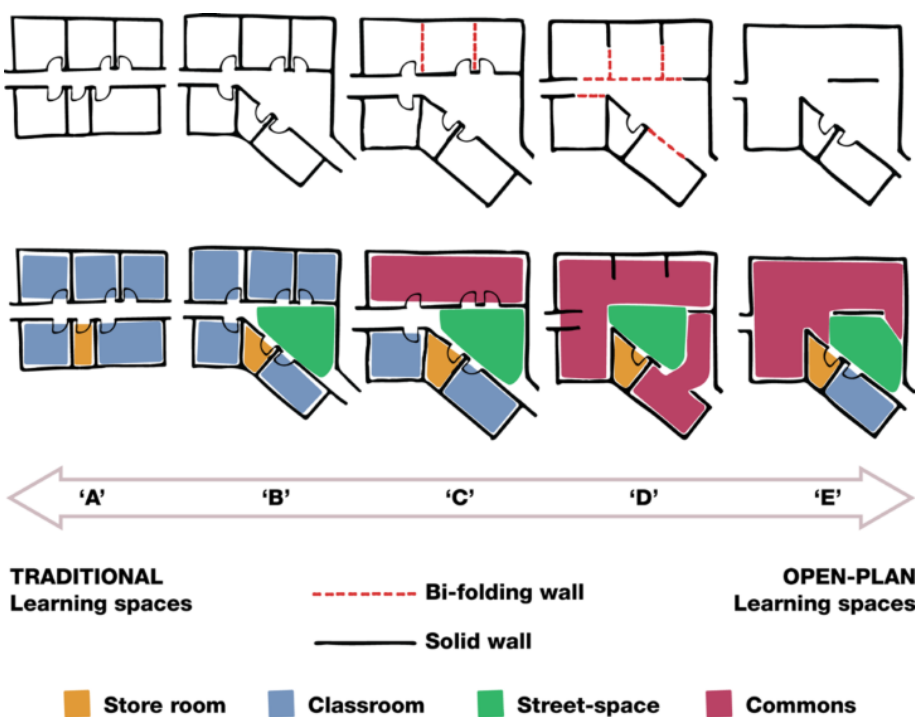

Figura 2 - Tipos de espaço de aprendizagem.

Fonte: (IMMS; CLEVELAND; FISHER, 2016, pág. 4).

A partir dos tipos de espaços apresentados, Dovey e Fisher (2014) descrevem 6 diferentes tipos de abordagens de ensino. As atividades variam com práticas que envolvem toda a turma até práticas de estudo individual. As 6 abordagens de ensino estão descritas no Quadro 1 abaixo:

com recursos das novas tecnologias.

2 "An Innovative Learning Environment (ILE) is defined in our project as the product of innovative space designs and innovative teaching and learning practices. Only when these two phenomena are successfully merged do we produce an innovative learning environment. A design may be deemed 'innovative' but it only becomes an ILE once its in habitants (teachers and students) teach and learn innovatively within them". (MAHAT et al., 2018, pág.8) 
Quadro 1 - Abordagens de ensino.

\begin{tabular}{|l|l|}
\hline $\begin{array}{l}\text { Apresentação } \\
\text { (25-150 estudantes) }\end{array}$ & $\begin{array}{l}\text { Alunos ou professores apresentam para grupo } \\
\text { amplamente passivo. Tais atividades facilitam a } \\
\text { comunicação ou informação. }\end{array}$ \\
\hline $\begin{array}{l}\text { Interação ampla } \\
\text { (25-75 estudantes) }\end{array}$ & $\begin{array}{l}\text { Atividades que mudam facilmente de grandes para } \\
\text { pequenos grupos e vice-versa. Frequentemente, } \\
\text { são organizados em subgrupos de 4-6 que podem } \\
\text { ser subdivididos. Facilita a aprendizagem entre } \\
\text { pares e o ensino em equipe. }\end{array}$ \\
\hline $\begin{array}{l}\text { Interação média } \\
\text { (10-25 estudantes) }\end{array}$ & $\begin{array}{l}\text { Atividades com um fluxo de movimento } \\
\text { semelhante ao anterior, mas com um tamanho de } \\
\text { grupo menor e, geralmente, um professor. }\end{array}$ \\
\hline $\begin{array}{l}\text { Interação criativa } \\
\text { (10-25 estudantes) }\end{array}$ & $\begin{array}{l}\text { Atividades interativas, com ênfase em aprendizado } \\
\text { prático, além de canetas e teclados, com acesso a } \\
\text { uma variedade de recursos que incluem materiais } \\
\text { de arte, atividades em laboratórios ou ao ar livre. }\end{array}$ \\
\hline $\begin{array}{l}\text { Interação pequena } \\
\text { (2-5 estudantes) }\end{array}$ & $\begin{array}{l}\text { O modelo de aprendizagem é baseado em } \\
\text { problemas e entre pares com pequenos grupos } \\
\text { autônomos, que podem assumir a } \\
\text { responsabilidade pelo seu aprendizado. }\end{array}$ \\
\hline $\begin{array}{l}\text { Reflexão } \\
\text { (1 estudante) }\end{array}$ & $\begin{array}{l}\text { Atividade individual (personalizada) que inclui } \\
\text { leitura, escrita ou pesquisa. }\end{array}$ \\
\hline
\end{tabular}

Fonte: (DOVEY; FISHER, 2014, pág.47, tradução nossa).

Para além de um espaço físico "inovador", práticas inovadoras devem ter lugar nesse ambiente. As práticas inovadoras precisam desenvolver novas habilidades, como a capacidade de resolver problemas e as habilidades conhecidas como os " $4 \mathrm{C}$ 's": Criatividade, Colaboração, Comunicação e Criticidade. O ensino necessita ir além da transmissão de conhecimento, o aluno precisa envolver-se de forma ativa nos processos de ensino e aprendizagem. A OECD (2017), no capítulo I do The OECD Handbook for Innovative Learning Environments (Manual da OCDE para Ambientes Educativos Inovadores), apresenta 7 princípios que devem ser considerados na aprendizagem, quando se projetam ambientes educacionais:

1- Incentivar o engajamento e a motivação dos alunos, reconhecendo os estudantes como os principais participantes da aprendizagem, garantindo o envolvimento ativo de todos eles.

2- Promover a interação, a cooperação e o trabalho em grupo: deve-se valorizar a interação com os outros, aluno-aluno, aluno-professor. Essa interação pode ser realizada cara a cara ou à distância, os alunos precisam desenvolver a capacidade de cooperar e aprender juntos.

3- Considerar as motivações e as emoções dos alunos. A aprendizagem não deve considerar apenas a parte cognitiva, mas as emoções e motivações dos alunos, que são essenciais para o sucesso da aprendizagem. 
4- Compreender as diferenças de cada aluno, pois cada um tem uma bagagem quando chega à escola, ou seja, seus conhecimentos prévios. É importante conhecer as diferenças entre os discentes e adaptar as atividades conforme as necessidades de cada um. A avaliação precisa valorizar o progresso individual de cada aluno.

5- Valorizar as diferentes habilidades, apoiando e explorando suas potencialidades, deve-se valorizar as diferentes habilidades e promover o seu aperfeiçoamento. $O$ aluno precisa ser motivado e incentivado, perceber sua capacidade de aprimoramento e receber apoio para explorar suas potencialidades.

6- Oferecer feedback formativo para a aprendizagem. A avaliação é essencial para o aprendizado dos alunos, mas essa deve ser coerente com os objetivos da aprendizagem. Os estudantes necessitam receber feedback para desenvolver e aprimorar seu conhecimento. A avaliação precisa mudar esse julgamento de aprovado/reprovado e certo/errado, haja vista o processo de avaliar precisa ser muito mais do que julgar. A avaliação precisa observar como os alunos conseguem aplicar seus conhecimentos em novos problemas, os alunos precisam aprender com os erros.

7- Integrar conhecimentos de várias disciplinas por meio de resolução de problemas. Os alunos precisam vivenciar situações nas quais se envolvam com problemas reais, que possam buscar conhecimento e aplicá-los em situações além das apresentadas em sala de aula pelos professores.

Para que esses princípios sejam colocados em prática, alunos e professores precisam compreender esses novos espaços e perceberem seus papéis dentro desse novo cenário.

\section{Inovação disruptiva}

As inovações podem ser caracterizadas de duas formas: inovação incremental e inovação disruptiva. A inovação incremental são mudanças realizadas a fim de trazer melhorias para um determinado produto, mas a característica principal dele é preservada. Como exemplos, podemos citar: aviões com maior autonomia de voo, computadores que processam com maior velocidade, baterias de telefones celulares que duram mais tempo, entre outros (CHRISTENSEN; HORN; JOHNSON, 2012). A maioria das inovações, no campo da Educação, é vista como melhoria.

A inovação disruptiva (ID) muda a ideia e o conceito do produto, causando uma ruptura em um padrão. Esse termo foi utilizado inicialmente no campo empresarial. A ID traz um novo conceito e na maioria dos casos cria novos setores da economia ou mesmo elimina setores tradicionais até então consolidados. Em geral, agrega novos consumidores que antes não possuíam acesso ao produto ou serviço antigo.

Clayton M. Christensen trouxe esse conceito para o campo educacional como uma possibilidade de proporcionar avanços na Educação. O novo produto deve romper com o padrão antigo e para que haja sucesso, a tecnologia disruptiva precisa ser empregada em aplicações que não tenham alternativa viável. Atingir um novo público é mais importante para o sucesso da inovação disruptiva do que a própria tecnologia. Essa inovação não deve competir com o mercado já existente. Quando a Apple lançou o seu computador 
pessoal Apple II, criou um mercado completamente novo para a computação, pois esse modelo foi feito como brinquedo para crianças. Com isso, ela focou em consumidores que não tinham acesso a esse mercado.

Christensen, Horn e Johnson (2012) abordam um exemplo de inovação disruptiva no ensino: o aprendizado via internet. $O$ ensino on-line pode ser considerado uma inovação disruptiva quando sua implementação não for pensada como concorrente do ensino tradicional. Essa inovação teve sucesso exatamente porque atingiu uma clientela que antes não tinha acesso à determinado tipo de formação. Logo, aqueles que não podiam ser atendidos pelo sistema tradicional, passaram a ter a oportunidade de aprender algo, como um idioma, uma profissão, etc. Esses nova clientela é composta por aquelas pessoas que trabalham e não têm tempo de frequentar um curso presencial, comunidades isoladas que não têm possibilidade de ter um professor, pessoas que queiram ter contato com um idioma diferente, entre outras.

O ensino online poderá novamente se tornar uma inovação disruptiva quando chegar à sala de aula e conseguir promover um novo tipo de ensino que seja centrado no aluno, personalizado e que favoreça as diferenças.

Como a própria definição apresentada de AEI destaca, este ambiente só pode ser considerado inovador se alunos e professores aprendem e ensinam de forma inovadora. É importante interpretar o que é um AEl. É mudança de espaço? É inserção de tecnologias? É um ambiente que permite desenvolver diferentes tipos de atividades (em grupo, individuais) e com recursos de tecnologias, mas o professor precisa reconhecer que esse novo ambiente exige uma mudança de sua prática. Não é só mudança de espaço e inserção de recurso, é um caminho para mudança de metodologias.

\section{Metodologia}

Nossa pesquisa foi realizada entre os meses de setembro a dezembro de 2017 em uma escola particular e 3 escolas públicas de Portugal que vem implementando o projeto dos AEl. Durante o processo de pesquisa, realizamos entrevistas com 9 professores e acompanhamos algumas atividades conduzidas no $\mathrm{AEI}$ das escolas. Os professores serão identificados por P1, P2, P3, P4, P5, P6, P7, P8 e P9.

Antes de entrevistarmos os professores, tivemos acesso a vídeos com aulas gravadas em alguns AEI. Após assistir essas aulas, enviamos e-mails para os professores convidando-os para participar da entrevista.

Após esta etapa, alguns professores desmarcaram a entrevista e outros aceitaram conversar sem gravar o áudio. Esse fato já produziu um fato a ser analisado. Esses professores tinham receio de falar coisas que eles acreditavam que não iria agradar à entrevistadora. Logo, optaram por não se envolver no processo de análise do AEI.

Uma primeira hipótese foi levantada. Esse novo conceito de sala de aula pode acabar sendo rejeitada devido ao não reconhecimento daquele espaço como uma "verdadeira sala de aula". O AEI pode provocar medo e insegurança não só por inserir novas tecnologias no cotidiano da escola. A mudança da configuração do espaço com 
zonas de aprendizagem diferenciadas faz com esse novo ambiente pareça não familiar, causando estranhamento.

Nesse sentido, alguns professores podem rejeitar o $\mathrm{AEI}$ por falta de habilidade em utilizar seus recursos. Esse docente pode considerar que ensinar é um processo de transmissão de conhecimento e que o formato das carteiras enfileiradas responde melhor a sua concepção de ensino. As crenças e concepções dos professores sobre o ensino e a aprendizagem (ADMIRAAL et al., 2017; ERTMER, 1999; ERTMER et al., 2012) vão influenciar as formas de uso desse ambiente.

Procuramos analisar as falas daqueles que concordaram em serem entrevistados, ainda que sem gravação em três categorias:

Rejeição: o AEI, esse novo ambiente, rompe com os padrões da sala tradicional, essa mudança pode causar rejeição tanto por parte dos alunos como dos professores. Aqueles que se negaram a dar entrevistas, mesmo não verbalizando numa entrevista sua visão podem ser considerados nessa categoria.

Affordance: Quando os professores não identificam o AEI como ambiente de ensino-aprendizagem, podendo ressignificá-lo e adaptá-lo de acordo com concepções tradicionais de ensino e aprendizagem. Para que os professores possam explorar 0 potencial de um AEl, eles precisam perceber o espaço como familiar, identificando cada elemento e sua funcionalidade no processo no qual estão inseridos.

Poder Mágico: Quando alunos e professores acreditam que a sala por si só (aparelhos, software, mobiliários) resolvem todos os problemas do ensino. Nessa visão atribui-se ao artefato um poder mágico de solucionar todos os problemas. Os professores consideram esse novo ambiente como a "salvação" para os problemas da educação.

\section{Análise}

Este trabalho procurou compreender como os professores portugueses, que trabalham em escolas que estão implantando o projeto europeu das "Salas de Aula do Futuro", vêm interagindo com a proposta em seu cotidiano. Para tanto, foram coletados dados a partir de três fontes básicas: (A) observação de vídeos gravados de aulas; (B) observação de atividades no campo (C) entrevista com professores.

Nesse trabalho faremos uma análise dos dados obtidos através dessas três fontes buscando compreender a realidade através de categorizações. Foram detectadas três posturas básicas frente a tentativa de implantação dos AEI. Elas foram denominadas por nós de (a) Rejeição, (b) Affordance e (c) Poder Mágico.

A primeira postura (rejeição) já foi observada antes mesmo do início da realização das entrevistas. Em visita a um desses AEI em setembro de 2016, durante um evento, tivemos a oportunidade de conversar com um coordenador de AEI. Ao perguntarmos como era o uso da sala, ele respondeu que os professores não usavam muito e que tinham certa resistência. Essa postura foi confirmada logo no primeiro contato direto com os professores, já em 2017. Ao enviarmos e-mails para agendar entrevistas, alguns deles desmarcaram o encontro e outros não aceitaram que a entrevista fosse gravada por quaisquer meios (vídeo ou áudio). Alguns desses professores foram os protagonistas de 
vídeos de aulas que foram observadas. Nesses vídeos já se podia observar que eram aqueles com menor conforto no uso do novo espaço. Eles se sentiam inseguros para falar de algo que, possivelmente, rejeitassem. Em uma conversa informal, um deles nos confessou que usa pouco o espaço e que tinha medo da internet não funcionar no momento da aula ou dos artefatos falharem.

Durante as entrevistas podemos perceber nas falas dos professores a resistência em utilizar o AEl também pelos alunos. Um professor destacou que os alunos do ensino secundário ${ }^{3}$ são mais resistentes em usar a sala, e que os alunos mais fracos sentem mais motivados nessa sala. O Professor P6 relata:

Os alunos do ensino secundário, por incrível que pareça, são mais resistentes a essas tecnologias, do que os do básico, porque pensam assim: "Ah! na verdade, eu preciso estudar para o exame, preciso fazer exercício para exame". Ficam mais preocupados com a parte da avaliação propriamente dita do que com a própria parte do saber. (Professor P6)

Eu noto que há, realmente, os alunos, eu notei muito isso, os alunos mais fracos, ou que têm mais dificuldades têm tendência a estarem mais concentrados. Que é uma coisa que até é estranha, porque parece que é uma sala mais diferente, com uma disposição diferente, que eles poderiam estar mais dispersos e, na verdade, não, na verdade, eles estão mais concentrados. Notei isso nos alunos mais fracos. A parte positiva foi, basicamente, esta, a negativa foi, realmente, os alunos melhores que normalmente não gostam. (Professor P6)

Os alunos com melhores resultados, das séries mais avançadas, geralmente, não gostam de estar sempre nessa sala. Preferem as aulas "tradicionais", pois acreditam que essas vão prepará-los melhor para os exames. Essa rejeição está diretamente ligada não só a falta de habilidade em usar o $\mathrm{AEI}$, mas às concepções de ensino e aprendizagem tradicionais, que eram consideradas como mais eficientes em termos de competitividade nos exames de acesso à universidade. Isso reforça uma velha crença de que não adianta mudar os ambientes com suas metodologias se as avaliações não forem repensadas em paralelo. Já os alunos com rendimentos mais baixos, nesses espaços, ficam mais concentrados e, geralmente, apresentam mais habilidades para utilizar os artefatos tecnológicos.

A segunda postura foi denominada de affordance, palavra inglesa sem tradução direta para o português. Esse conceito é bastante utilizado na área do desenho industrial e refere-se a objetos que são projetados e quando colocados em uso não tem sua função identificada de imediato pelo usuário. Existem objetos novos que encontramos no nosso ambiente que podem assumir diferentes formas, mas logo que olhamos identificamos sua função, mesmo que sua forma não tenha relação com aquela que conhecemos. A partir de uma simples interação conseguimos identificar sua função. Quando falamos de affordance precisamos considerar duas variáveis: propriedades (do objeto) e capacidades (do agente). A forma de utilizar o AEI em seu potencial está diretamente ligada com a relação do indivíduo com esse ambiente, ele precisa reconhecê-lo como uma sala de aula.

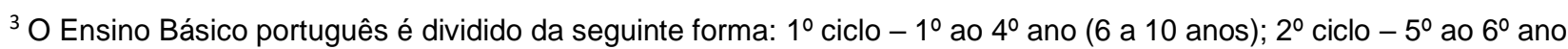

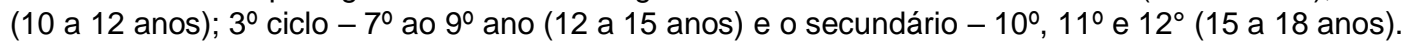


Affordances fornecem pistas de como se podem operar as coisas. Com relação ao AEI é importante compreender as affordances do espaço para que os professores possam desenvolver novas abordagens de ensino e perceber o ambiente como uma possibilidade de mudança de suas práticas. Se ele não reconhece essa afordance, ele adapta ao tradicional sem ressignificá-lo. A affordance do espaço oferece oportunidades de novas configurações para sala. Sobre a affordance do espaço, podemos observar a fala do professor P6, a seguir:

Por vezes o professor tem tendência a dispersar [...], porque lá está a mobilidade das cadeiras é tudo muito bonito, mas entretanto um aluno te chama e aqueles alunos ali estão a fazer outra coisa, e acabamos por dispersar. (Professor P6)

O professor P6 tem um olhar operacional para o espaço, vê o AEI mais como um espaço difícil de operar porque não se enquadra na aula tradicional e, por isso, os alunos se dispersam. Se o professor não reconhece a affordance da configuração do espaço, por exemplo, tende a adaptá-lo ao tradicional, colocando os alunos enfileirados e não considerando a potencialidade para o qual aquele desenho foi pensado e projetado.

A terceira postura refere-se a visão messiânica e ao poder mágico aplicado ao espaço. Em alguns vídeos de divulgação dos AEI pode-se perceber que existe a tentativa de apresentá-los como a solução para os problemas educacionais. Podemos perceber indícios do discurso que denominamos de "Poder Mágico" do AEI com relação a motivação dos alunos, na fala a seguir:

E dos estudos que nós fazemos e dos relatórios que chegam das outras escolas, os alunos que vêm pra cá é que eles desmotivam, não gostam de aprender, não querem estar na sala de aula [...] E na verdade todos os nossos alunos vieram para este projeto ano passado, com exceção de um ou outro. A maioria deles prosseguiram os estudos ou passaram para escolas profissionais, porque queriam cursos ligados ao cinema, ao teatro [...] E equacionaram a hipótese de prosseguir os estudos, que antes de cá chegar diziam: "ah eu não quero vir para a escola, não quero isso". [...] realmente mostra um sucesso dos alunos, uma mudança significativa nos resultados, uma motivação de virem as aulas [...] (Professor P7)

Essa postura, do Poder Mágico, atribuída ao AEI pode levar a acreditar que o espaço, por si, opera o milagre da motivação estudantil e ao verdadeiro aprendizado. Porém, um olhar mais crítico nos leva a perceber que o espaço sem as metodologias, uma nova avaliação e uma nova postura do professor frente ao ensino não representará inovação. Essa postura, da crença no poder mágico do espaço, precisa ser problematizada.

Importa assinalar que uma aula agendada, em um espaço como um AEI, gera uma expectativa por parte dos alunos em realizar atividades diferentes, que ainda não realizaram em outras aulas. $\mathrm{O}$ acesso rápido à informação, o aumento dos softwares e aplicativos disponíveis para aplicação no contexto de sala de aula cresce a cada instante.

O professor, nesse mundo de possibilidades, não consegue acompanhar tal desenvolvimento e aprender a utilizar tais ferramentas. Quando chegam a aplicar algumas 
ferramentas no ensino podem ser surpreendidos pela reação dos alunos, como foi o caso do Professor P2, ao preparar uma aula utilizando comando de respostas, que destaca:

E vou buscar a mala, é uma mala grande onde estão todos os comandos, e eu a fazer um grande suspense, a pensar que ia dar uma grande novidade e eles viram para mim e dizem assim: "- Afinal, era isso!? Já fizemos isso tantas vezes com o professor de Música". E eu pensei: “- Oh! Eu aqui todo entusiasmada, a fazer assim um grande [...] e eles eram pequeninos e tal, nunca fizeram, nunca trabalharam com isto ainda, por acaso eu nunca tinha comentado com o professor, com o colega de Música, se eles já tinham utilizado aquilo?" [...] Portanto, eu achava que ia dar uma novidade, e eles: "-Oh! Afinal, era só isso, já fizemos imensas vezes com o professor de música, nós sabemos como isso funciona". (Professor P2)

Como já foi definido anteriormente, um espaço para ser considerado um AEI precisa de um desenho inovador e que alunos e professores aprendam e ensinem de forma inovadora. Trabalhar nesses espaços requer do professor abordar os conteúdos dentro de uma perspectiva mais contextualizada, tal como por meio de problemas e questionamentos. Esse "novo" espaço gera desconforto e insegurança tanto nas práticas dos professores quanto nas expectativas dos alunos, sobre o processo de ensino e aprendizagem. Logo que adentram e conhecem esse novo mundo vem a dúvida sobre a eficácia dessa inovação em relação ao jogo escolar de provas e promoções anuais que aprenderam a jogar desde muito jovens.

Desse modo, ensinar e aprender em um novo conceito de sala de aula é um processo complexo não só para os professores, como também para os alunos. Os docentes encontram dificuldades para inovar em suas práticas, que podem ser reflexos da falta de habilidades para utilizar as tecnologias e o desenho do AEI, da falta de formação, da insegurança, assim como de suas crenças sobre o processo de ensino e aprendizagem (ERTMER, 1999; ERTMER; OTTENBREIT-LEFTWICH; TONDEUR, 2015). Os alunos que precisam realizar uma prova para o ingresso nas Universidades, ou como forma de avaliação nas escolas, não percebem o ensino nesses espaços como capaz de prepará-los. Além dos exames, esses alunos têm uma grande expectativa, quando estão trabalhando nesses espaços, de que as atividades sejam "sempre" diferentes.

Podemos afirmar que tanto professores como alunos precisam compreender esse novo espaço. O processo de transformação das práticas realizadas nos $\mathrm{AEI}$ e da compreensão dos mesmos precisa ser trabalhado com professores e alunos. Esses dois grupos precisam reconhecer as formas de ensinar e aprender nos novos ambientes educativos.

\section{Considerações Finais}

Os AEl propõem um novo modelo de sala de aula que rompe com o conceito tradicional. Sendo assim, é importante discutir e refletir sobre esse novo "produto" a partir do conceito de inovação disruptiva.

As inovações disruptivas mudam o conceito de um produto, rompem com o velho padrão. Podemos, nesse sentido, pensar no AEl como uma inovação que quebra com o 
conceito tradicional da sala de aula, aquela que valoriza o ensino por transmissão, com uma configuração padronizada em que os alunos permanecem sentados enfileirados conduzidos pelo professor, semelhante a um avião, um trem (SERRES, 2015). O AEl é um ambiente flexível, que permite desenvolver tanto atividades em grupos, como individuais, com apoio das novas tecnologias e com um novo papel do professor.

Esse novo conceito de sala vem para ser uma inovação disruptiva, mas acaba encontrando uma série de barreiras durante os processos de implementação. Neste trabalho identificamos três possíveis posturas assumidas por professores e alunos: a) Rejeição, b) Affordance e c) Poder Mágico, que configuram algumas das barreiras que podem surgir nos processos de inovação nas escolas. Essa nova sala de aula não pode ser comparada e adaptada aos métodos tradicionais de ensino e avaliação. Ela permite desenvolver competências diferentes das desenvolvidas no ensino tradicional. Esse novo ambiente causa certo estranhamento - Heterotopia - conceito existente em Foucault (2003). Os professores pensam que esse não é o seu lugar, sentem-se desconfortáveis e despreparados. Já os alunos, preocupados com o modelo tradicional de avaliação, acabam não reconhecendo o ensino nesse ambiente como passível de preparação para os exames.

Para que o AEI promova mudanças nas formas de ensinar e aprender, professores e alunos precisam compreender esse ambiente.

Uma das escolas pesquisadas tem direcionado o uso do AEI para trabalhar com alunos de vários níveis de ensino ( $7^{\circ}, 8^{\circ}$ e $9^{\circ}$ ano), alunos estes, que por vários motivos não completaram os estudos na idade certa. Como destacamos ao longo deste trabalho, os AEI vão enfrentar uma série de obstáculos ao serem colocados para concorrer lado a lado com as salas tradicionais, pois não se encaixam nos modelos de salas e metodologias onde a maioria dos professores foi formada.

Uma das características da inovação disruptiva é a inclusão no mercado de novos consumidores que antes não tinham acesso a ele. Nesse caso, por comparação, podemos perceber que os $\mathrm{AEI}$ acabam sendo mais bem aceitos por aqueles que foram excluídos do sistema tradicional, exatamente por não terem completado a série na idade certa ou não conseguiram desenvolver e compreender os conteúdos por simples transmissão dos professores. Para esses excluídos os AEl têm um grande potencial de entrada. Como acontecem com todas as disrupções bem-sucedidas, estas precisam ser direcionadas para os não consumidores tradicionais, num primeiro momento, até que ganhem força dentro do sistema. Acreditamos que inicialmente a implementação dos AEI, com foco nestes alunos, seja um dos caminhos para o sucesso destes espaços. Assim como o trabalho por projetos, nesses espaços, para os alunos mais avançados.

Byers e Imms (2017) mostram que os AEI da Austrália e Nova Zelândia não estão provocando grandes mudanças nas práticas dos professores e poucos docentes estão explorando o potencial desses espaços. Os professores encontram uma série de barreiras, tanto no plano das concepções sobre educação, construídas ao longo da vida, como no plano prático, construído ao longo da experiência profissional. No plano prático, há deficiências de habilidades e competências para lidar com os espaços descentralizados, com as novas Tecnologias da Informação e Comunicação e com as 
metodologias ativas. Os professores não foram formados para o uso dessas práticas nem as vivenciaram ao longo da vida. No plano das crenças (mentalidade), construímos diversos valores ao longo da vida sobre o que é uma boa aula, o que é um bom professor ou sobre os conteúdos (e só eles) que o aluno deve saber ao sair da escola. Grande parte das experiências acumuladas nos últimos anos tem demonstrado que os professores não sabem de que forma o espaço pode ser utilizado para potencializar suas práticas. Tentam converter o novo naquilo que acreditam ser uma boa aula. Mais do que reverter a falta de treinamento para o uso das tecnologias e do espaço, é necessário haver uma mudança de mentalidade, um sentido de reinvenção de si.

\section{Referências}

ADMIRAAL, W. et al. Teachers in school-based technology innovations: A typology. Computers \& Education, v. 114, p. 57-68, 2017.

BANNISTER, D. Guidelines on Exploring and Adapting LEARNING SPACES IN SCHOOLS. European Schoolnet, Dez. 2017. Disponivel em: <http://www.indire.it/wpcontent/uploads/2018/04/Learning_spaces_guidelines_ENG.pdf>. Acesso em: 29 maio 2018.

BYERS, T.; IMMS, W. Solution? Evolution? or Revolution? Learning Spaces, Teaching Times: Birmingham, v. 3, n.3, p. 50-58, 2017.

BYERS, T.; IMMS, W.; HARTNELL-YOUNG, E. Comparative analysis of the impact of traditional versus innovative learning environment on student attitudes and learning outcomes. Studies in Educational Evaluation, v. 58, p. 167-177, Sept. 2018.

CHISM, N. V. N. Challenging Traditional Assumptions and Rethinking Learning Spacesl. In: OBLINGER, D. G. Learning Spaces. [S.I.]: Educause, 2006. p. 2.1-2.12.

CHRISTENSEN, C. M.; HORN, M. B.; JOHNSON, C. W. Inovação na sala de aula: como a inovação disruptiva muda a forma de aprender. Porto Alegre: Bookman, 2012.

ERTE. Ambientes Educativos Inovadores. Disponível em: <http://erte.dge.mec.pt/ambientes-educativos-inovadores>. Acesso em: 25 maio 2018.

ERTMER, P. A. Addressing First- and second-order barriers to change: strategies for technology integration. Educational Technology Research and Development, v. 47, n. 4, p. 47-61, 1999.

ERTMER, P. A. et al. Teacher beliefs and technology integration practices: A critical relationship. Computer \& Education, v. 59, n. 2, p. 423-435, 2012.

ERTMER, P. A.; OTTENBREIT-LEFTWICH, A. T.; TONDEUR, J. Theachers' beliefs and uses of technology to support 21 st-century teaching and learning. In: FIVE, H.; GILL, M. G. International Handbook of Research on Teachers' Beliefs. New York: Routeledge, 2015. p. 403-418.

EUROPEAN SCHOOLNET. Future Classroom Lab. 2016. Disponível em: <http://fcl.eun.org/documents/10180/13526/FCL+learning+zones+Dec+2016/a091a7617a63-443e-afe0-d1870e430686>. Acesso em: 20 ago. 2017. 
FOUCAULT, M. "Outros espaços". In: Ditos e escritos III - Estética: Literatura e Pintura, Música e Cinema. Rio de Janeiro: Forense Universitária, 2003. p. 411-422.

IMMS, W. et al. Type and Use of Innovative Learning Environments in Australasian Schools ILETC Survey n. 1., 2017. Disponivel em: <http://www.iletc.com.au/publications/reports>. Acesso em: 8 out. 2018.

IMMS, W.; CLEVELAND, B.; FISHER, K. Learning environments evaluation. Snapshots of emerging issues, methods and knowledge. Rotterdam: Sense Publishers, 2016.

LEAHY, G. The modern classroom: Strategic insights for school leaders. Blackburn: Promethean, 2016.

LINHARES, R. N.; FERREIRA, S. L. Reflexões sobre o perfil tecnológico dos professores do núcleo de Itabaiana/Sergipe no curso de formação para PROUCA. In: 35ª REUNIÃO ANUAL DA ANPED. Anais... Porto de Galinhas : [s.n.]. 2012.

MAHAT, M. et al. Innovative Learning Environments and Teacher Change: Defining key concepts. LEaRN, Melbourne, 2018. Disponivel em: <http://www.iletc.com.au/publications/reports>. Acesso em: 9 out. 2018.

MONAHAN, T. Flexible Space \& Built Pedagogy: Emerging IT Embodiments. Inventio, v. 4, n. 1, p. 1-19, 2002.

MORAN, J. M. Ensino e aprendizagem inovadores com apoio de tecnologias. In: MORAN, J. M.; MASETTO, M. T.; BEHRENS, M. A. Novas tecnologias e mediação pedagógica. Campinas: Papirus, 2013. p. 11-72.

OECD. The OECD Handbook for Innovative Learning Environments. Paris: OECD Publishing, 2017.

PEDRO, N. Ambientes educativos inovadores: o estudo do fator espaço nas "salas de aula do futuro" portuguesas. Revista Tempos e Espaços em Educação, São Cristóvão, v. 10, n. 23, p. 99-108, 2017.

SEIXAS, L. V. S. Conectando a rede: recontextualizações do projeto "Um computador por aluno" (UCA) em uma escola municipal do Rio de Janeiro. Porto de Galinhas: Atas da 34ª Reunião Anual da ANPED, 2011.

SERRES, M. Polegarzinha. Tradução de Jorge Bastos. 2. ed. Rio de Janeiro: Bertrand Brasil, 2015. 96 p. 